\title{
PROGRAM EXCELLENCE SOLUTION UNTUK MENURUNKAN WAKTU PENGERJAAN REMANUFACTURING UNIT KOMATSU PC2000-8 DI PT UT SITE KALIMANTAN SELATAN
}

\author{
Vuko A.T. Manurung ${ }^{1, a}$, Lukyawan Pama Deprian ${ }^{2, b}$, Yohanes Tri Joko \\ Wibowo ${ }^{3, c}$ \\ ${ }^{1}$ Program Studi Mesin Otomotif Politeknik Manufaktur Astra, Indonesia \\ ${ }^{2}$ Program studiTP3 PolitreknikManufaktur Astra \\ avuko.manurung@polman.astra.ac.id, byohanes.trijoko@polman.astra.ac.id, \\ lukyawan.deprian@polman.astra.ac.id
}

\begin{abstract}
Abstrak.
Dengan berjalannya waktu unit alat berat akan mengalami penurunan performance. Guna mengembalikan unit ke performance awal maka dilakukan Proses remanufacturing disingkat Reman. Reman adalah suatu aktifitas yang dilakukan untuk mempertahankan unit alat berat mendekati performance ketika pertama kali di buat.

PT UT site Adaro dipercaya oleh customernya untuk melakukan Reman secara khusus unit eskavator tipe Komatsu PC 2000-8. Dalam pelaksanaannya terjadi keterlambatan pelaksanaan proses pengerjaan menjadi 80 hari. Oleh karena itu dibuat suatu program untuk menurunkan waktu proses pengerjaan (leadtime) total sehingga menjadi 45 hari atau turun sekitar 44\%.
\end{abstract}

Kata kunci. Reman, PC 2000-8 leadtime

\section{Abstract.}

With the passage of time the heavy equipment unit will experience a decrease. In order to return the unit to its initial performance, the Reman manufacturing process is abbreviated as Reman. Reman is an activity carried out to keep heavy equipment units close to performance when first created.

PT UT site Adaro is trusted by its customers to do Reman specifically for Komatsu PC 2000-8 type excavators. In the implementation there was a delay in the implementation of the work process to 80 days. Therefore, a program was created to reduce the total leadtime to 45 days or down by $44 \%$. Keywords. Reman, PC 2000-8 leadtime 


\section{PENDAHULUAN}

Berkaitan dengan salah satu budaya SOLUTION yang ada di PT UT yaitu Serve, Innovative, and Networkingmaka perlu dibuat suatu program guna meningkatkan produktifitas dalam hal pengerjaan proses REMAN(Remanufacturing) salah satunya dengan menurunkan waktu pengerjaan (lead time) REMAN dan juga harus diikuti dengan menaikkan unjuk kerja (performance) unit yang baik setelah di lakukan proses REMAN.

Biaya untuk setiap proses Reman dibatasi untuk setiap unitnya. Pembatasan tersebut dibagi menjadi dua katagori yaitu unit alat berat tipe roda (wheel) maksimum biaya yang dikeluarkan $40 \%$ dari haga baru dan untuk tipe rantai (track) maksimum biaya yang dikeluarkan $50 \%$ dari harga baru. Dengan demikian unjuk kerja (performance) dari unit yang mengalami REMAN akan mencapai 80\% kalau menggunakan unit baru.Target yang ditetapkan oleh customer PT UT adalah proses Reman akan mencapai PA (Physical Availability) sebesar 94\%.

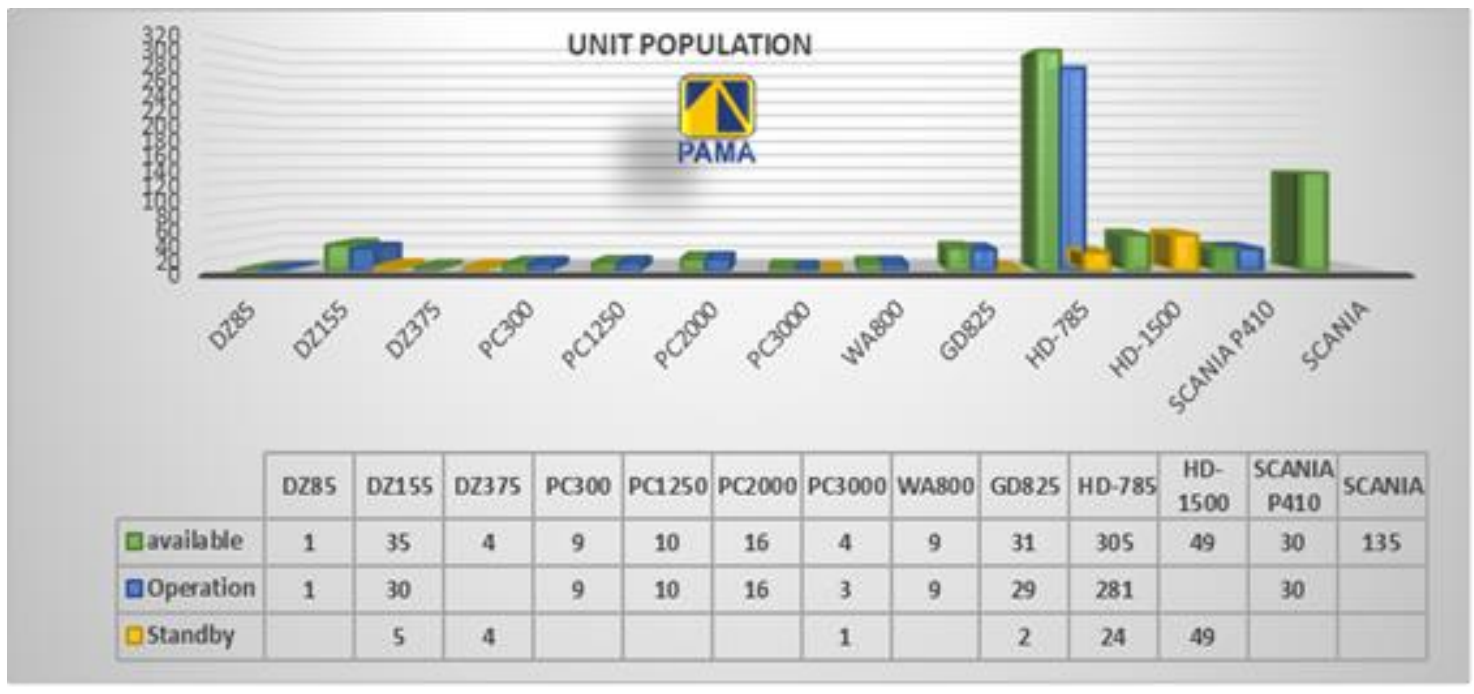

\section{Gambar 1. Populasi Unit yang adadilapangan}

Gambar 1, menunjukkan jumlah populasi unit yang ada dilapangan. Proses Reman diterapkan pada unit yang sudah memiliki lebih dari 40.000 jam pemakaian dan ada lebih dari 2 komponen besar yang harus diganti. 


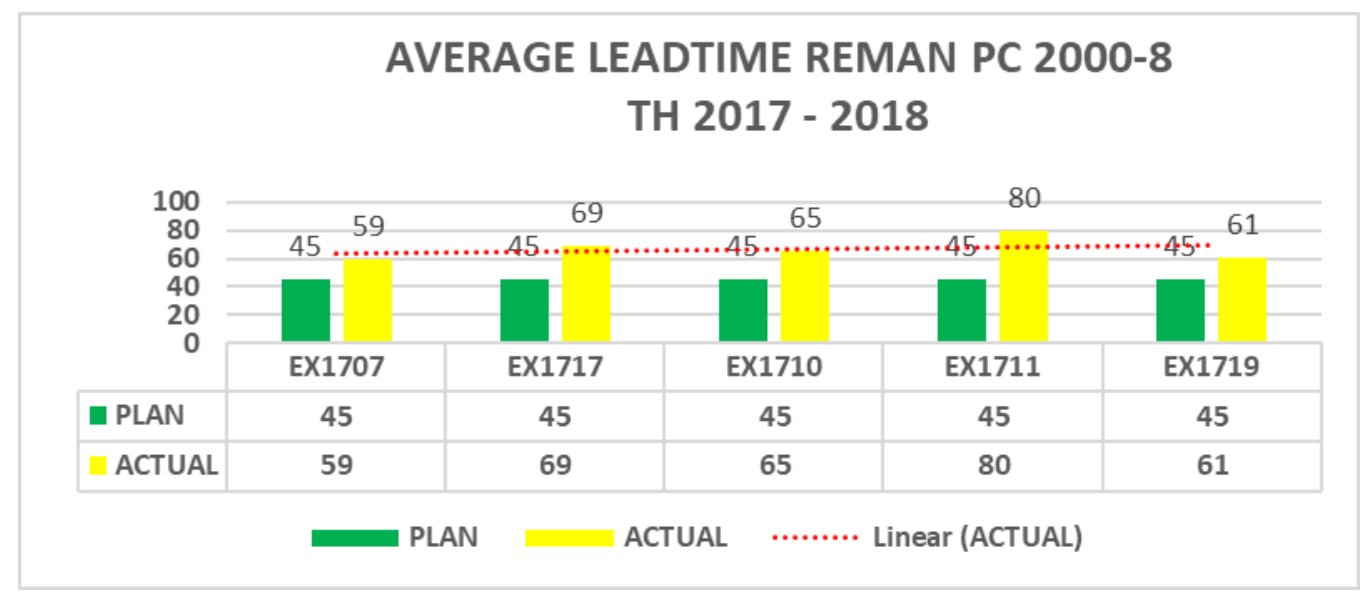

Gambar 2. Rata-rata waktu pengerjaan (leadtime) PC 2000-8

Dari gambar 2 terlihat waktu pengerjaan Reman masih diatas target yang diberikan yaitu selama 45 hari kerja, dan yang paling besar adalah unit PC 2000-8 dengan code EX1711.

\section{METODOLOGI PENELITIAN}

Untuk menemukan solusi dari permasalahan yang timbul maka digunakan salah satu tool management yaitu: diagram tulang ikan (fishbone diagram). Diagram tulang ikan ini sudah sangat lazim digunakan di grup Astra International sebagai alat untuk memmecahkan suatu persoalan yang timbul dilapangan. Persoalan yang ada dikelompokan dalam empatunsur yaitu people dan methode, tools serta machine. Gambar 3 adalah diagram tulang ikan yang mempermudah mencari penyebab masalah target proses Reman tidah tercapai.

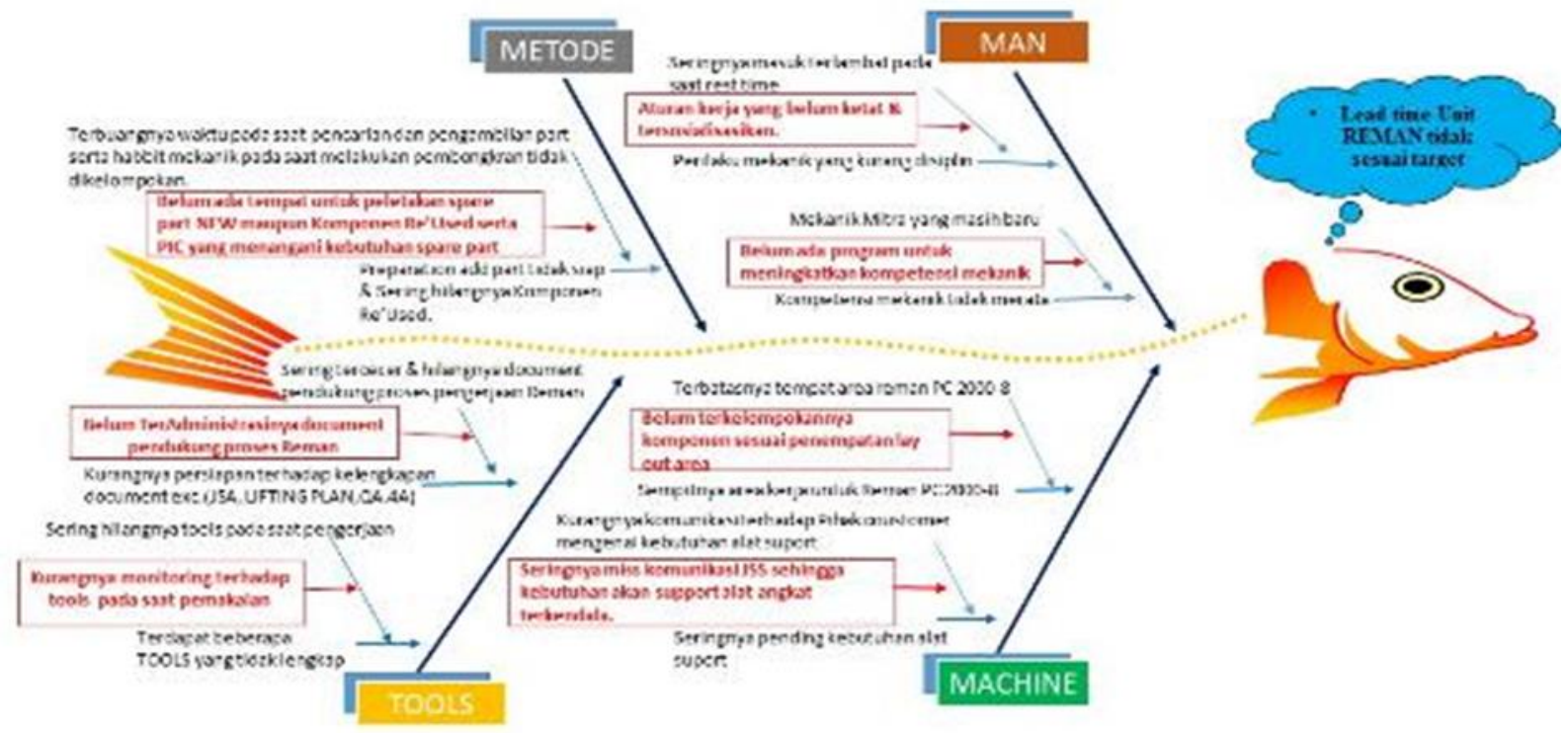

Gambar 4. Diagram Tulangikan (fishbone) 
Setelah dilakukan program solution excellence maka didapatkan hasil untuk leadtime pengerjaan proses Reman PC 2000-8 adalah sebagai berikut:

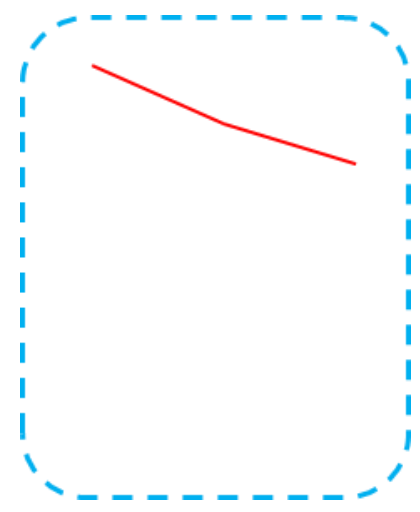

Gambar 5. Data sebelum dan sesudah dilakukan solution excellence

Dari data diatas terjadinya penurunan leadtime yang pada awalnya 80 hari turun menjadi 45 hari, meskipun masih terjadi selisih dari target sebanyak 5 hari. Adapun data penyumbang keterlambatan(delay job) yang masih terjadi sehingga mengakibatkan masih terdapat selisih antara target dan aktulal proses Reman PC 2000-8 adalah pada gambar 6 .

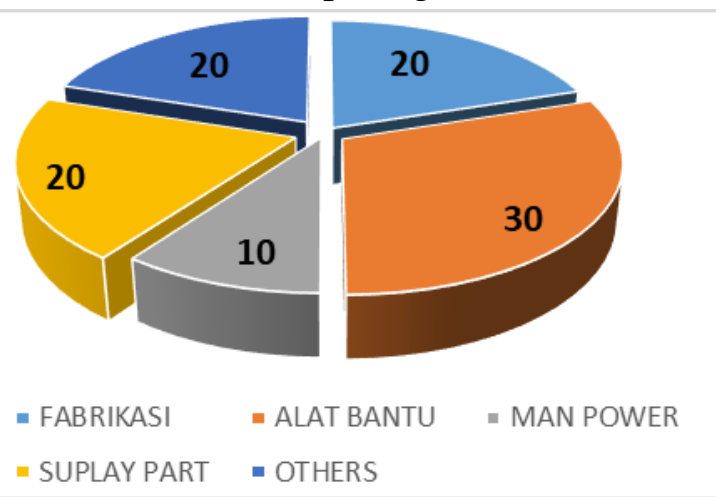

Gambar 6. Delay job (hours) Setelah dilakukan solution excellence

\section{Manfaat dari Program Solution Excellence}

Dengan menerapkan program solution excellence ini keuntungan yang diperoleh dari PT UT secara nyata adalah sbb:

Jumlah mekanik yang mengerjakan program ini adalah 5 orang dan pembantu mekanik (subcontracting) sebanyak 11 orang dengan waktu pengerjaan di bagi dalam 2 shift dan ada 1 orang mekanik serta 2 orang pembantu mekanik yang disiapkan untuk cadangan kalau ada yang berhalangan/tidak masuk kerja.Adapun jam kerja per shift adalah 10 jam.

Biaya rata-rata Mekanik per jam (manpower cost per hour) : Rp.190.000,00

Biaya rata-rata pembantu Mekanik per jam : Rp.38.000

Dengan demikian:

Biaya mekanik per hari $=2 \times 10 \times 2 \times$ Rp. $190.000,00=$ Rp.7.600.000,00

Biaya pembantu mekanik per hari $=4 \times 10 \times 2 \times$ Rp. $38.000,00=$ Rp. $3 \cdot 040 \cdot 000,00$ 
Jadi total pekerja langsung per hari adalah $=$ Rp.10.640.000,00

Sesuai dengan hasil kerja aktual sebelum dilakukan program solution excellence waktu kerja adalah 80 hari, sehingga total biaya mekanik langsung adalah:

$$
80 \text { x Rp. } 10.640 .000=\text { Rp. } 851.200 .000,00
$$

Dengan adanya program ini jumlah hari yang dapat kurangi adalah 30 hari, yang dikonversi dalam bentuk uang adalah sbb: 30 x Rp.10.640.000 = Rp.319.200.000,00

Dengan demikian biaya total pekerja (manpower total) yang dapat di hemat (oportunity cost) untuk satu unit adalah: Rp. 319.200.000,00untuk unit tipeEX 1741.

Sedangkan untuk tipe EX 1719 lamanya waktu proses Reman yang dapat dihemat adalah: 80-61 = 19 hari, sebesar: 19 x Rp. 10.640.000,00 = Rp. 202.160.000,00

Dengan demikian total biaya mekanik (direct manpower) yang dapat dihemat dengan melaksanakan program ini adalah: Rp. 319.200.000,00 + Rp. 202.160.000,00 = Rp. 521.360.000,00

\section{KESIMPULAN}

Program Solution Excellence yang diterapkan pada proses Reman unit PC 2000-8 di PT UT dapat disimpulkan:

a) Dapat meminimalisir terjadinya keterlambatan pekerjaan.

b) Meningkatkan kompetensi mekanik Subcont dan kepercayaan customer terhadap produktivitas proses Reman PC2000-8.

c) Menurunnya leadtime pengerjaan Reman unit PC 2000-8 mendekati waktu pelaksanaan yang di targetkan dan tidak melenceng jauh.

\section{DAFTAR PUSTAKA}

1. Materi Quality Introduction,2012, PT United Tractors,Tbk,Jakarta.

2.PTUnited Tractors,Tbk, 2012, Key Performance Indicator, sebagai bahan Review SBPRTeam,

Jakarta

3. Komatsu Ltd, 2003, Shop Manual Komatsu PC2000-8, Japan http://www.slideshare.net/ekostereo42/ 82-teknik-alat-berat-jilid-2 (online). 25,06,2015.

4. Manurung Vuko A T, Yohanes Tri Joko, Agung Gema Muhazir,2018, MengurangiKerusakan yang TidakTerjadwal (Unschadule Breakdown) KOMATSU PC 4000-6D dengan Program Kerja Super Touch Aim Maintenance di PT UT Area Kalimantan Selatan, Journal $\begin{array}{lllll}\text { Technologic, } & \text { Vol } & 9, & \text { No } & 2,\end{array}$

5. Technical Training Departement. (2012), BasicMaintenance. PT. United Tractors, Jakarta 
6. Technical Training Departement. (2012), Product Knowledge. PT. United Tractors,Jakarta 7.Huzij, Robert, Angelo Spano, Sean Bennett 2009, Heavy Equipment System Delmar. 8. T Gilles 2012, Automotive Service Inspection, Meintenance, Repair, 4th Edition, Delmar5. 9.S Bennett 2009, Medium/Heavy Duty Truck Engines, Fuel and ComputerizedManagementSystem, 3th edition Delmar. 